\title{
Meeting Women's Needs. Women and Girls With Disabilities in the Practice of Rehabilitation Projects
}

\author{
Jenny Kern
}

\section{INTRODUCTION}

The topic Participation of Girls and Women with Disabilities in Rehabilitation Projects in Developing Countries could fill an entire conference. And because of the growing critical awareness that the experience of disability for women and men differs, I am hopeful that meetings such as the one on Local Concepts and Beliefs about Disability in Different Cultures in Bonn, May 1998, will continue to examine the gender perspective. Rehabilitation must be examined within the larger social contexts that shape the lives of women with disabilities. Women with disabilities are women first. And they also have disabilities. For both, they are devalued by their societies. For those living in developing nations where health care, adequate nutrition, jobs, mobility equipment and many things people of the Western world take for granted are scarce, the difficulty of being a woman with disabilities is certainly compounded.

I begin with brief general descriptions of the status of women, people with disabilities and women with disabilities. Relying primarily on their descriptions, I then identify the barriers most women and girls with disabilities face in accessing rehabilitation services in the so-called Third World. Using the Whirlwind Network as a model to examine women's absence from rebabilitation projects I describe Whirlwind Women as a possible recipe for women's participation. I then describe the shifting models of both Community Based Rehabilitation, or CBR, and women in development projects and discuss disabled women's opportunity to participate in both with examples of potentially successful projects. Finally, I examine the emerging international movement of women with disabilities that is and will continue to be a critical antidote to the oppression of women with disabilities. 


\section{The Status of Women: Less than Equal}

Regardless of the ways in which women experience their gender and despite the importance it has to them as individuals, the cultures and communities in which they live place their own values and expectations on the female gender. Notwithstanding huge shifts in many cultures, the social status of women remains, at the end of the 20th century, vastly inferior to that of men. They have far less power, money and influence than they should, considering that they number more than half of the world's population. Their work as tenders of the family and caregivers, when this is counted as work, is undervalued and unpaid. Their work outside the home is valued less than that of men, as well. In addition, they endure drastically high levels of poverty, illiteracy and violence because they are women. Gender based crises, such as the trafficking of women and girls, forced prostitution, sweatshop labor, female genital mutilation and the severe human rights abuses against women and girls are beginning to receive international attention thanks to concerted efforts of feminist activists.

\section{The Status of People with Disabilities: Evolving Struggles}

The number of people with disabilities is rising. In the year 2000, approximately 13 percent of the world's population, or 846 million people, will be people with disabilities. And of those, four-fifths will reside in developing countries (Davis 1998). The experience of disability, although certainly not amorphous, has its own range of cultural meanings depending on the particular culture and disability. Factors such as the gender, race and economic status of the person with a disability influence attitudes, as well. The universal truth remains, however, that like women, people with disabilities as a class suffer from poor social status, disproportionate poverty and deprivation by virtue of the disability. In the U.S.A., a country with civil rights protections against discrimination in employment, only 28 percent of people with disabilities of working age who want to work were employed in 1995 (National Council of Disability 1996: 59). For women with disabilities, the statistics are worse (ibid.).

When women pioneers of the Disability Rights and Independent Living Movement organize, they are historically, politically and philosophically linked to the U.S. Civil Rights Movement that emerged in the 1960s and 1970s. The transformation of people with disabilities from 
caste to class and of disability policy from good will to civil rights did not evolve suddenly but after a long-fought strategic effort by millions of participants. The new movement demanded independence and community living, not institutionalization; full inclusion, not segregation; disability rights, not special favors. As the free speech, black power, gay and lesbian rights, anti-war, feminist and other movements arose to examine the oppressive forces imbedded in American society, such as racism and sexism, people with disabilities, too, questioned the biological definition of disability. Just as feminists identified institutionalized sexism as a societal evil that devalued women because of their socially defined gender roles, disabled people exposed many of the myths associated with living with disability. Activists knew from experience that public policy reflecting myths, stereotypes, fears and ignorance about disability rather than actual physical or mental limitations posed the deepest oppression defining their struggles. In addition, lack of access to schools, town halls, polling places and recreational facilities, for example, kept disabled people virtually segregated as second class citizens. This further exacerbated public misperceptions. In turn, disabled activists began to speak out, rally and protest against limiting policies and oppressive attitudes.

Due in large part to this activism, over the past 30 years various political, legal and social factors have combined to shift the disability paradigm. The prevailing view of disability in the 1960s was one of a charity or medical model, in which dependent and ill patients, disconnected from the rest of society, should be individually belped by means of patronizing policies, including legally sanctioned segregation. The alternative view regarded disability from a civil rights perspective in which individuals with disabilities recognized that it was the institutional barriers to full participation in society that needed a cure, rather than their physical or mental limitations. An example of this analysis integrally connected to the Independent Living Movement is that it is not a wheelchair user's inability to climb stairs that is a problem but the lack of alternative access, such as ramps. The charity model social expectation is that such a person could not participate (in school, work, social life) because she is unable, passive, pitiful, sick, dependent, weak, etc. Under the civil rights model, by contrast, it is clear that she is instead systematically excluded by architectural and attitudinal barriers, her disability notwithstanding. As with similar oppressed groups that found power in group identity or rallied around their minority status, the social formation of the Disability Rights Movement was both a result of and a major impetus behind legislative and judicial change. Activists lobbied policy-makers to address such basic issues as architectural access, legal segregation in schooling 
and institutionalization of people with disabilities. The struggle for civil and human rights protections, and the shift from the medical or rehabilitation model to an independent living or civil rights model, challenges all the stereotypical notions people have had about disability for centuries. ${ }^{1}$ The myth that disabled means unable cannot be sustained in this emerging conception of disability human rights (Kern 1997).

The case of Uganda illustrates what is possible. In spite and because of decades of repression under authoritarian regimes, the disability movement of Uganda achieved some significant victories in the new Ugandan Constitution:

The right of persons with disabilities to respect and human dignity shall be recognized by the state and society and the state shall take appropriate measures to ensure that persons with disabilities realize their full mental and physical potential. (Disability Action and Awareness Newsletter 1995: 9)

The Constitution requires that five members of Parliament represent people with disabilities, including at least one disabled women's representative. In addition, the deaf community of Uganda lobbied successfully for inclusion of Sign Language as an official language.

\section{The Status of Women with Disabilities: At the Bottom of the Heap}

Where femaleness and disability intersect, cultural values, expectations and attitudes come close to being universally negative. As many others have written, by virtue of our status as women and people with disabilities, we are doubly disadvantaged and face the dual discrimination of both sexism and disability bias. Women with disabilities and those isolated in rural regions, the vast majority in developing countries, face even more barriers to inclusion in their societies. Low cultural expectations and stigma remain the norm, resulting in our own self-devaluation as disabled women. Negative societal stereotypes of disabled women include the notion that we are passive, weak, asexual, dependent, unable to have spouses, children, jobs or rights. These myths reinforce and contribute to our low social status as, truly, the poorest of the poor. Women with disabilities are more likely than other women or than disabled men to be violated, institutionalized, sterilized, isolated, denied access to our own children. It is by far the exception that we are encouraged to fulfill our human potential. 
As a Ugandan woman writes of her disability experience:

The disadvantages of disabled women begin in childhood, because parents look on their disabled daughters as a curse from God. As in any other African society, all girls have very little chance to go to school. They are to stay at home, help their mothers in household activities, get married and bring cows and wealth to the family. The situation worsens when you are disabled. First of all, there is no hope of you bringing cows and other material wealth to the family since it is widely believed that you will not marry because you are disabled. As if that was not enough, parents say they won't waste their money sending disabled children to school when they don't have enough resources to send their able-bodied children. (Kinene 1995: 7)

The prevalent attitude that women and girls with disabilities cannot help support the family or successfully marry allows a family to neglect its daughters' education. This cultural devaluation of females with disabilities remains commonplace in societies worldwide.

\section{Women and GirLs With Disabilities in Rehabilitation: BARRIERS TO ACCESS ${ }^{2}$}

What is rehabilitation for women with disabilities in developing countries? Rehabilitation provides access to the tools, education, training and peer support needed for full integration into the social and political life of their communities. Identified barriers to disabled women's participation in all aspects of society, including rehabilitation services, include (Boylan 1991: 28):

\section{Societal Barriers}

- poverty

- illiteracy

- lack of education, training and skills

- rural women's isolation from services

- inaccessible buildings and transportation to services

- parental overprotection

- cultural conflicts between rehabilitation and local customs

- low self-esteem

- burdens of single parenting 


\section{In addition, women with disabilities}

- are more likely to be destitute, under-nourished, unemployed; without family support, illiterate and without vocational training;

- have less access to rehabilitation and appropriate services.

\section{Male Privilege}

The common practice in many cultures of devaluing women and girls in favor of males presents grave disparities:

- disabled girls have higher mortality rates than disabled males. Males are often given preference when food is scarce (Abu-Habib 1997: 73). This is true of assistive aids and devices such as wheelchairs, as well. In Uganda, at least 100,000 people need wheelchairs, due primarily to polio. While more than half are women, only 1 percent of women have them.

- only 1-2 percent of disabled children in developing countries receive any primary education; disabled boys are more likely than girls to attend school (IDEAS 1995).

\section{ACCESS to Rehabilitation}

The opportunities for rehabilitation in developing countries are bleak for everyone when we consider that 80 percent of people with disabilities worldwide reside in developing countries where only 10 percent of all rehabilitation services occur (Boylan 1991: 28). Given this stark reality and the facts that only 2 percent of disabled people in developing countries receive any rehabilitation whatsoever (UNESCO 1995: 13) and that "women and girls with disabilities receive inadequate-if any-rehabilitation services because the very limited available resources are directed toward adult men" (Lewis/Sygall 1997: XII) we must acknowledge that girls and women with disabilities are vastly underserved and examine the root causes. The preference for rehabilitating war veterans before others poses difficulties for women, girls and other civilians in need of services, as well. In Palestine, the division was clear:

the high profile given to disabled people as a result of the Intifada had inevitably meant a focus on the physical injuries of young men, $(t)$ his focus deflected the disability debate away not only from women, who also suffered during the Intifada, but also against those with congenital or non-physical impairments. (Atshan 1997: 55) 
According to women with disabilities living in developing countries, if they survive their injuries or disabilities, some of the factors restricting disabled women and girls' access to services include negative attitudes in the form of traditional concepts and prejudices. In rural areas, for instance, women traditionally stay at home and are responsible for caring for family and household. ${ }^{3}$ In societies where women are regarded as an investment, a disabled woman is often (considered) worthless and therefore educating her is a waste (ibid.). Rehabilitation programs appear to have been designed to suit disabled men's aspiration to recover their masculinity and sexuality, while the needs and aspirations of disabled women are often ignored (Abu-Habib 1993: 4). African cultures and religions, as practiced today, oppress women. Women do most of the household chores while men relax; they work twice as hard as men (Tandon 1995: 19). In Zambia one woman writes:

Because women with disabilities are multiply handicapped in that they are female, illiterate, disabled and live in rural areas, they do not benefit from the available rehabilitation services as they legally could. (Boylan 1991: 28)

Most rehabilitation services are male-oriented. Education is an uphill struggle for disabled women and society seems to take for granted that disabled men should be employed but that disabled women are to remain dependent throughout their lives (ibid.).

Women with disabilities have not, until very recently, been integrated into mainstream community development initiatives. Even the International Labor Organization, which strives to insure 50 percent female participation in its technical cooperative projects, falls drastically short. Of 1,900 disabled persons trained or receiving vocational support in ILO sponsored projects, only 21 percent were women (cf. note 2). There are notable exceptions which I describe later, but the general rule remains that without specific outreach and attention to the needs of disabled women, women's programs and disability projects will not be inclusive of women with disabilities. The several women with disabilities I am working with in East Africa demonstrate their creativity and entrepreneurial skills daily as they support their families alone, make and market crafts, navigate difficult physical environments and, in two cases, run for regional governmental posts. What they need is access to start-up capital and technical support to fulfill their business potential. Their creativity and skills have been honed by virtue of their ability to survive, but they continue to struggle with the burden of poverty. 
If we recognize that women with disabilities experience less access to and more discrimination in rehabilitation projects than men (Boylan 1991: 25), the goal should be clear: to work together to devise and implement strategies for including women with disabilities more fully in rehabilitation and development projects to learn income-generating skills.

\section{THE WhirLWind NetWork: ATtempts at INCLUSion for Women Meet Strong Resistance.}

The story of the Whirlwind Network demonstrates that even a rebabilitation project by and for people with disabilities, in which women with disabilities have been active and instrumental, poses problems for women's ongoing participation. In most of the developing world, even today, the best hope of obtaining a wheelchair rests with Western charity: and this really means a non-repairable hand-me-down wheelchair, inappropriate for essentially everything but the hallways of a hospital, with someone else pushing. This is not exactly a prescription for independence. Without any mobility, the disabled people of developing countries remain hidden away, in isolated villages, with no hope of meeting others with disabilities, often dying from preventable pressure sores and other infections.

In 1980, with start up funds from USAID and a collaborative training with Ralf Hotchkiss, several Nicaraguan teenagers started building an early version of the Torbellino, or Whirlwind, for disabled people in their communities. This was the first shop in the Whirlwind Network; the Network has expanded in the last 18 years to include 35 shops in 25 countries, with each shop building a version of the Whirlwind. As some shops succeeded and others failed, the Nicaraguans realized that shops run by the users of the chairs themselves were most likely to stay in business. Shops run by wheelchair riders make the most durable chairs, and have a history of coming up with more improvements - new inventions - than the shops run by wheelchair non-users. Over time the Nicaraguans developed a philosophy that guides the development of the Whirlwind Network today: people with disabilities - especially the wheelchair riders themselves - must be leaders at every level, from design to sales, in the making of the Whirlwind. Disability leadership is essential, both to creating the quality of wheelchairs that we need and to the struggle for the most basic human rights of those of us with disabilities. It is the 
riders navigating our lives on wheels whose input is vital. But where was women's participation?

\section{WHIRLWIND WOMEN}

Whirlwind Women was founded in 1994, to fill the gap and provide training and support for women interested in creating their own mobility options. Over an eighteen-year period women have made major design and technological contributions to the ever-evolving Whirlwind wheelchair, such as the jump seat or second seat used to assist in transferring, permit access to the ground, transport children or firewood and also serve as a seat for a pit latrine, if no outhouse seat is accessible. Other contributions by women include the triangular side frame and stabilizing chain that keeps the wheelchair together when folded. Women's input into the design, however, did not translate into support for their involvement in the shops where men dominated in every way. The sad truth is, without sufficient support, even the most skilled women technicians rarely have remained long in male dominated wheelchair shops. Historically, those who stay have been isolated and assigned to the traditional women's work of sewing the chair fabric. In the Philippines, of the twenty shop workers only one was a woman, and she sewed the fabric. The reasons have many cultural aspects such as endemic machismo and sexism, low expectations, condescension and patronizing attitudes. Even the notion that a woman could weld, drill, saw and build a wheelchair is revolutionary in most communities worldwide. Providing the opportunity is even more difficult. In Palestine, cultural barriers prohibit women from working in the shop and receiving training. In other regions, women allowed in shops are still considered less able, yet even their presence threatens men. A classic story is of men assisting women with a task, and then walking away with the necessary tool she was using. Other problems include men being possessive of heavier, more dangerous jobs. This tendency to overprotect is compounded when the woman technician has a disability. When I was building my first Whirlwind, I worked with a very nice fellow who felt he should do everything for me including most of the welding, instead of allowing me to learn each task with the rest of the class. I happen to like welding, and insisted. I got my chance, but I could easily have been dissuaded from learning. And there are classic harassment issues that women everywhere face. When one young woman was teaching in Mexico, she had to deal with men not 
listening to her, flirting with her and touching her inappropriately. Only because an older Mexican woman supported her did the men back off and take her seriously.

There are positive examples of women receiving sufficient support to fully participate, thereby strengthening the whole shop or training. Just as in the disability rights or any traditionally male dominated movement, the key is for enough women to participate and to support each other that a critical mass forms, serving to strengthen the women's confidence and resolve.

- In a Cambodian shop, a blind woman leads a team of five blind workers who earn their living spoking all the wheels. By now, her team has spoked more than 8,000 wheels. Several other women work in the shop on a variety of tasks, lending crucial moral support.

- In Nicaragua, a few isolated women started out as mechanics. They were subsequently pushed out of the shops due to hostile work environments caused by the men. Now the women are forming coalitions to remedy past discrimination. Currently, three groups led by disabled women plan to repair wheelchairs after they secure tools and training.

- In January 1997 in Limuru, Kenya, Whirlwind Women conducted a week-long intensive training in basic tool use for women and worked with three women from Disabled Women's Network and Resource Organization DWNRO of Uganda and three Kenyan women. The women's intensive training preceded a three-week course in Whirlwind wheelchair design and production attended by twelve male mechanics. The pre-training for women fostered a sense of community necessary to ward off feelings of inability and insecurity in the shop. Whirlwind Women and the DWNRO representatives, independent, strong single mothers supporting their families, built two Whirlwinds and left the training determined to work toward opening a womenrun Whirlwind production shop in Uganda where no folding chairs are currently made. The project will begin this summer.

- In Kenya, Peninah Mutinda has started a woman run Whirlwind building shop with a grant from the Global Fund for Women, to compete with other local shops. 


\section{Community BASEd Rehabilitation}

The major shifts in the thinking about rehabilitation that are manifest in Community Based Rehabilitation or CBR are emerging as a potential way to combat some barriers to rehabilitation services for all disabled people through promoting social integration, equal opportunity and community involvement of people with disabilities (Boylan 1991: 25; Tandon 1995). In theory, context-oriented programs and projects sensitive to individual, family and community needs should begin to bridge the huge gap between disabled women and their access to necessary medical, vocational and social services. To the extent that CBR remains participatory, community driven and controlled, and promotes skills, confidence and empowerment for, not control over, people with disabilities, the community-centered philosophy of CBR should bode well for women's increasing participation in training activities.

\section{Women in DeVelopment}

Similarly, the emerging consciousness of women's pivotal role in development broadens the spectrum of opportunities for all women in developing countries. The international development community led by entities such the Grameen Bank, a micro-lender that began in Bangladesh, has acknowledged that investing in women makes good business sense. "Grameen found that by lending to women, profits were used to improve the family's quality of life, and led to a rise in women's status." Women, especially working in groups, have demonstrated their skills when given the opportunity to decrease their economic marginality. As such, they are credible risks for loans. Now, disabled women are seeking ways to tap into this and other development resources and mainstream women's projects as a means to support their families and increase autonomy. ${ }^{5}$ (Lewis/Sygall 1997: XI) While both CBR for people with disabilities, evolving development models and vocational training for poor women offer greater possibilities for women with disabilities, a risk is that women with disabilities may fall between the cracks of these progressive trends. Disabled women indicate that they may not yet be adequately benefiting from these services. A 1990 survey determined that of 55 successful skills training projects for women in Africa, none involved women with disabilities (Boylan 1991: 28). Recommendations from the survey state: 
in planning income-generating activities, experts, after having assessed local and/or national markets, should take care that disabled women are not only introduced to activities traditionally occupied by women. Often, there are viable alternatives to knitting and weaving.

And disabled women at a conference in Entebbe agree that "women should not limit themselves to traditional types of activities, such as secretarial work. They should look into new opportunities such as electronics, radio repairs, computers, etc." (Tandon 1995: 19).

Some positive examples of projects designed to be inclusive of disabled women's needs are:

- Improved Livelihood for Disabled Women in Botswana, Zambia, Zimbabwe, Lesotho and Swaziland, an ILO project funded by the German government, works to change attitudes about women with disabilities. It also

promotes participation of women with disabilities in mainstream projects, to ensure access to productive employment, education, training and community activities. (Lewis/Sygall 1997: 50)

Examples of income-producing activities women with disabilities were trained to do were bookbinding, cardboard furniture making, leatherwork, cement block making, secretarial and photocopying services. In addition, working with both women's groups and national organizations of disabled people, disabled women were trained to run a maize-grinding mill (ibid.: 52).

- In Tanzania, CHAWATA, the Tanzania Association of the Disabled has a Women's Development program, formed in 1992. They support women's participation in CBR, vocational rehabilitation, production of mobility aids and revolving loan programs. Women's projects include: tailoring, groceries, weaving, pottery, gardening and sale of commodities in markets (ibid.: 38 ).

- The Ugandan Disabled Women's Whirlwind Wheelchair Project will bring together disabled and non-disabled women in a collaborative pilot project, teaching wheelchair building skills as a means of generating income and of producing wheelchairs for Ugandans with disabilities. In each case, women work together, with support, to earn income while filling a community need.

Such models of rehabilitation that recognize the considerable skill that women with disabilities bring to their lives every day will shift the focus from what needs to be fixed? to given the abilities present, what are ways to optimize independence, bealth and income generating skills and opportunities? The key, I believe, is to include women with disabilities in 
the problem solving. Ask us what we need and how we propose to get it and what needs to be done to help. Support us in strengthening our movements from the ground up. Acknowledge that we have expertise from our life experiences. Listen to our suggestions; support us and learn from our successful projects. Work with us as resources and allies as part of a team, not as outsider experts.

\section{Antidote to Exclusion ANd Oppression: The EmERgence of AN INTERnAtIonal MOVEMENT Of ACTIVIST WOMEN WITH Disabilities}

Many of us have been brought up to have limited expectations of ourselves and our future quality of life; to believe that we are not entitled to a voice, a place, a vote. Yet increasing numbers of disabled women are finding value within ourselves and pride in our collective identity. ${ }^{6}$ Despite the strong cultural links between women and people with disabilities worldwide, neither the Disability Human Rights Movement nor the Women's Human Rights Movement has historically sought to include issues of women with disabilities in their political agendas (BlackwellStratton 1988: 307; O’Toole 1997: 127; Lakkis 1997). Fortunately, a growing international movement of activist women with disabilities recognizes the value of all girls and women with disabilities as a vital part of the human family. We are speaking out about negative cultural values and lack of rights, services and opportunities, forced sterilization, female genital mutilation and eugenics, among other things. We know our skills and abilities have been consistently overlooked, that our existence has been devalued and our quality of life denied. And we are working to end these forms of discrimination by educating our families, communities, health care and rehabilitation providers in ways that fully integrate women with disabilities into societies.

Roseangela Berman Bieler, a Brazilian activist leader, reminds us:

It is hard to ponder over disabled women's grievances separately from the fundamental social problems (such) as prejudice, ignorance, segregation and lack of civil rights. (Bieler 1997: 97)

Fueled by the desire to address those problems, and unwilling to be unrepresented or spoken for at another international women's conference, 200 women with disabilities from over 30 nations gathered outside of Beijing in 1995 for the International Symposium on Issues of Women with Disabilities sponsored by the World Institute on Disability and 
Mobility International, U.S.A. At the NGO Forum and official U.N. conference we joined together to put our stamp on the international women's movement and assert that we are indeed a necessary force for badly needed social change in communities everywhere. During the NGO Forum, we protested about lack of access to the meetings as we named the problems that we face worldwide: poverty, violence, low self esteem, lack of access to buildings, sign language interpreters, education, training, employment, adequate healthcare, rehabilitation, adaptive equipment and transportation. And we, along with our allies, shared strategies to make those changes in our communities all over the world. Delegates to the official conference representing disabled women successfully lobbied for inclusion of language into the Platform for Action to: "ensure that girls and women of all ages with any form of disability receive supportive services." ${ }^{8}$ This recommendation mainstreams the needs of women with disabilities, broadening the potential impact of the 1993 U.N. Standard Rules on the Equalisation of Opportunities of Persons with Disabilities. ${ }^{9}$ Both officially acknowledge the need to include disabled women in rehabilitation programs.

We came together again in Bethesda, Maryland last June at the International Leadership Forum for Women with Disabilities, the largest meeting ever dedicated to the international issues of disabled women. Approximately 600 women with disabilities met to keep the momentum going: to network, develop ideas for solving our own problems and celebrate our common links. It is this powerful collective energy that is igniting grassroots activities of disabled women in thousands of communities from Africa to Latin America. Other regional gatherings of women with disabilities in Brazil, Munich, Entebbe and Oregon strengthen our commitment to global and local social change. We know that we as disabled women, working in groups with other disabled women, must define our own futures. We are learning that this takes organization, technical skills and financial support from international development organizations. We are beginning to demonstrate that despite the myths about us, disabled women are serious about inclusion in rehabilitation, social services and equal access to society. 


\section{CONCLUSION}

A wheelchair or crutch or adaptive device is only part of the rehabilitation process, as are skills training and employment support. These are tools allowing the potential for a fuller life. Women with disabilities are emerging as leaders in this movement, seeking tools and rehabilitation to maximize their potential, more fully participate in their communities, and fight the considerable attitudinal, social and architectural barriers that keep us marginalized.

\section{Notes}

1 Wendell, 1996, see generally chapter two, The Social Construction of Disability. See also A. Asch and M. Fine 1988: 9-12; T. Degener and Y. Koster-Dreese 1995: 15.

2 International Labor Organization Survey in 1990. In: Inside Rehab. No. 6 April 1990.

3 Disabled Women in Countries Cooperating with SHIA, p. 7.

4 Grameen Foundation, U.S.A., brochure.

5 In September 1998, fifteen disabled women leaders from around the world will attend a micro-credit summit with Mobility International U.S.A. to devise ways to participate in the development model of micro-loans in ways that accommodate their needs.

6 Disabled People's International-Europe Women's Committee press release for International Women’s Day March 1994-DAA newsletter March 1994.

7 Previous United Nations conferences on women include Mexico City, 1975, Copenhagen, 1980, Nairobi, 1985. Accessibility, disabled participants and disability issues were virtually non-existent at these conferences, even though the Nairobi conference took place during the U.N. International Decade of Disabled Persons.

8 The Beijing Declaration and Platform for Action, The Fourth World Conference on Women, U.N. Doc. A/CONF.177/20 (1995). (Health section). Issues of women and girls with disabilities are included in sections 60(a), 73, 82(a), (g), 83(a), 84(k), 102, 107(c), (o), 110(d), 115, 125(m), 127(d), 180(f), (j), 197(a), 209(k), 226, 232(p), 233(a)(b), 259, 270, 272, 278(d), 280 (c).

9 United Nations Documentation A/48/96 (1993). 


\section{REFERENCES}

Abu-Habib, Lina (1997): Gender and Disability, Women's Experiences in the Middle East, OXFAM: Morris.

Atshan, Leila (1997): "Disability and gender at a cross-roads: a Palestinian perspective”. In: Abu-Habib, Lina, Gender and Disability. Women's Experiences in the Middle East: OXFAM, pp. 49-62.

Asch, A./Fine, A. (1988): "Beyond Pedestals", In: A. Asch/A. Fine (eds.), Women with Disabilities: Essays in Psychology, Culture and Politics, Philadelphia: Temple University Press.

Berman, Bieler, Roseangela (1997): "Taking Charge. Women Leaders with Disabilities". In: C. Lewis and S. Sygall (eds.), Loud Proud and Passionate, Oregon: Eugene, pp. 97-99.

Blackwell-Stratton et al. (1988): "Smashing Icons: Disabled Women and the Disability and Women's Movements". In: A. Asch /M. Fine (eds.), Women with Disabilities, Philadelphia: Temple University Press, pp. 306-320.

Boylan, Esther (1991): "Rehabilitation, Education, Employment-Elusive Goals", In: E. Boylan (ed.), Women and Disability, London: ZED-Books Ltd., pp. 22-43.

Degener, T. (1995): “Disabled Persons and Human Rights: The Legal Framework",

In T. Degener/Y. Koster-Dreese (eds.), Human Rights and Disabled Persons, International Studies in Human Rights Volume 40.

Kern, Jenny (1997): Across Boundaries: “The Emergence of an International Movement of Women with Disabilities”, In: Hastings Women's Law Journal, Volume 8, Number 2, pp. 236-240.

Kinene, Betty (1995): "Overcoming Obstacle to the Integration of Disabled Peoples”, In: UNESCO sponsored report as a contribution to The World Summit on Social Development, Copenhagen: United Nations, Economic and Social Council, Overcoming Obstacles to the Integration of Disabled People.

Lakkis, Sylvana (1997): "Mobilising women with physical disabilities: The Lebanese Sitting Handicapped Association”, In: Lina Abu-Habib, Gender and Disability, Women's Experiences in the Middle East, OXFAM: Morris, pp. 43-55.

Lennard Davis (1998): “An Eighth of the World”, In: Review of Nothing About Us Without Us by James Charlton, The Nation, March 30.

Lewis C./Sygall S. (eds.) (1997): Loud Proud and Passionate. Including Women with Disabilities in International Development Programs. Mobility International, Oregon: Eugene.

IDEAS (International Disability Exchanges and Studies) Project 2000, Factsheet: Women and Disability. Factsheet prepared by Rehabilitation International and the World Institute on Disability for the use of delegates to the 4th World Conference on Women and associated NGO Forum events.

National Council on Disability (1996): Achieving Independence: The Challenge for the 21st Century (report), July 26. 
O’Toole (1997): “Taking Charge: Women Leaders with Disabilities”. In: C. Lewis and S. Sygall (eds.), Loud Proud and Passionate, Oregon: Eugene, pp. 127-128. Tandon, Yash (1995): Sustainable Development and Persons: The Process of Self-Empowerment with Disabilities, Washington D.C.: African Development Foundation.

Wendell, Susan (1996): The Rejected Body, London: Routledge. 